\title{
Early Combination Therapy with Linagliptin and Metformin in People with Type 2 Diabetes Improves Glycemic Control to HbA1c $\leq 6.5 \%$ without Increasing Hypoglycemia: Pooled Analysis of Two Randomized Clinical Trials
}

Qian Lv · Jie Shen · Lin Miao · Binqi Ye - Cornelia Schepers •

Arian Plat · Yongquan Shi

Received: March 5, 2020 / Published online: April 23, 2020

(C) The Author(s) 2020

\section{ABSTRACT}

Introduction: Clinical guidelines suggest a glycated hemoglobin A1c (HbA1c) target of $\leq 6.5 \%$ for type 2 diabetes patients with short duration of disease, few comorbidities and/or long life expectancy-provided this goal can be achieved safely. We explored whether initial

Qian Lv and Jie Shen contributed equally to this work.

Digital Features To view digital features for this article go to https://doi.org/10.6084/m9.figshare.12102717.

Q. Lv · Y. Shi $(\bowtie)$

Department of Endocrinology, Shanghai

Changzheng Hospital, Second Military Medical

University, Shanghai, China

e-mail: young.stone@163.com

J. Shen · B. Ye

Boehringer Ingelheim (China) Investment Co. Ltd,

Shanghai, China

L. Miao

Lilly (Shanghai) Management Co. Ltd, Shanghai,

China

C. Schepers

Boehringer Ingelheim Pharma GmbH \& Co. KG, Ingelheim, Germany

\section{A. Plat}

Boehringer Ingelheim International $\mathrm{GmbH}$, Ingelheim, Germany

A. Plat

Eli Lilly and Company, Utrecht, The Netherlands combination treatment with the dipeptidyl peptidase-4 inhibitor linagliptin and metformin could provide better glycemic control (HbA1c $\leq 6.5 \%$ ) than metformin alone without increasing hypoglycemia.

Methods: We pooled and analyzed individual patient data from two randomized clinical trials of early combination therapy with linagliptin and metformin versus metformin monotherapy. The primary outcome in both trials was the change in HbA1c from baseline to week 24. We evaluated the percentage of patients who achieved HbA1c $\leq 6.5 \%$ at week 24 and the incidence of adverse events.

Results: Most (>70\%) of the 1160 patients analyzed were treatment naive, and more than half had had diabetes for $\leq 1$ year; mean baseline $\mathrm{HbA1c}$ was approximately $8.7 \%$. Combination therapy with linagliptin and metformin resulted in more patients achieving HbA1c $\leq 6.5 \%$ than metformin alone, both for a metformin dose of $500 \mathrm{mg}$ (40.1 vs. $22.9 \%$, respectively, odds ratio [OR] 2.84, 95\% confidence interval [CI $1.87-4.32$ ) and $1000 \mathrm{mg}$ (49.5 vs. $35.4 \%$, respectively, OR 2.28 , 95\% CI 1.54-3.40). Hypoglycemia occurred in $<3 \%$ of patients, with a comparable incidence between treatment groups. Other adverse events were also balanced between groups.

Conclusion: Early combination treatment with linagliptin and metformin can improve the chances of achieving tight glycemic control 
$(\mathrm{HbA} 1 \mathrm{c} \leq 6.5 \%)$ without increasing the risk of hypoglycemia or other adverse events.

Trial Registration: ClinicalTrials.gov, NCT00798161 and NCT01708902.

Keywords: Diabetes mellitus, type 2; Dipeptidyl peptidase IV inhibitors; Metformin

\section{Key Summary Points}

Why carry out this study?

Early achievement of tight glycemic control improves microvascular outcomes in type 2 diabetes, but its benefits could be offset by increased risk of hypoglycemia, particularly with regimens that include sulfonylureas or insulin.

We explored whether initial treatment with the dipeptidyl peptidase- 4 inhibitor linagliptin combined with metformin could elicit tight glycemic control (HbA1c $\leq 6.5 \%)$ without increasing hypoglycemia.

\section{What was learned from this study?}

The linagliptin/metformin combination more than doubled the odds ratio of achieving $\mathrm{HbA} 1 \mathrm{c} \leq 6.5 \%$ after 24 weeks of treatment compared to metformin alone, with a similar incidence of hypoglycemia.

Early combination of linagliptin and metformin may improve type 2 diabetes treatment compared with metformin alone.

\section{INTRODUCTION}

Over the past two decades, many new glucoselowering medications have been introduced for the treatment of type 2 diabetes (T2D) [1]. Despite this growing number of therapeutic options, however, glycemic management of T2D patients remains far from optimal. Although most major guidelines in the USA,
Europe and Asia recommend setting a HbA1c target of $<7 \%$ [2-5], a substantial proportion of patients with T2D do not achieve this level of glycemic control [6-10].

Tight glycemic control can bring long-term microvascular and possible macrovascular benefits, but it also may increase hypoglycemia, especially when classical glucose-lowering medications with high risk for hypoglycemia (insulin, sulfonylureas) are used for intensive therapy [11-14]. However, it is possible that the risk-benefit ratio of this strategy could be more favorable with the use of modern oral antidiabetic drugs (OADs), such as dipeptidyl peptidase-4 (DPP-4) inhibitors and sodium-glucose co-transporter-2 (SGLT2) inhibitors, which improve glycemic control without substantially increasing the risk of hypoglycemia $[15,16]$. Indeed, current guidelines from the American Diabetes Association (ADA) and the American Association of Clinical Endocrinologists (AACE) suggest setting a more stringent target for glycemic control $(\mathrm{HbA} 1 \mathrm{c} \leq 6.5 \%)$ for low-risk patients as long as this can be achieved without hypoglycemia or other iatrogenic adverse effects $[17,18]$. Such patients include those who have had T2D for only a short period of time, those without comorbidities, such as cardiovascular disease, and/or those with long life expectancy. Notably, the latest consensus report from the ADA and the European Association for the Study of Diabetes (EASD) recommends that patients with indicators of high cardiovascular risk, established cardiovascular disease, heart failure or chronic kidney disease receive second-line therapy (added to metformin) with a medication with proven cardiovascular benefit, such as an SGLT2 inhibitor or a glucagon-like peptide-1 (GLP-1) receptor agonist [19]. For others, the ADA/EASD report suggests a DPP-4 inhibitor as an option to add to metformin, particularly where there is a compelling need to avoid hypoglycemia [19].

Several clinical trials have demonstrated that early combination therapy using metformin with a modern OAD can significantly increase the number of patients achieving HbA1c $<$ $7.0 \%$ compared to the respective monotherapies, without increasing the incidence of hypoglycemia [20-23]. However, although most 
of these studies recruited early-stage T2D patients, they did not investigate the more stringent glycemic control target of $\mathrm{HbA} 1 \mathrm{c} \leq 6.5 \%$. One of these trials evaluated the DPP-4 inhibitor linagliptin [23]. We have conducted a post hoc pooled analysis of this study and of a similar randomized clinical trial of linagliptin [24] to explore the hypothesis that early combination therapy of linagliptin plus metformin would help a greater proportion of $\mathrm{T} 2 \mathrm{D}$ patients achieve HbA1c $\leq 6.5 \%$ than would metformin monotherapy, without increasing hypoglycemia.

\section{METHODS}

\section{Study Design}

This was a post hoc pooled analysis of two multi-center, phase III, double-blind, randomized clinical trials designed to investigate the glycemic efficacy and tolerability of the initial combination of linagliptin and metformin (NCT00798161: $n=791$ [24]; NCT01708902: $n=733$ [23]). In these trials, patients were aged $18-80$ years at screening with HbA1c of 7.5 to $<11.0 \%$ (for patients without any prior treatment in both studies) or of 7.0 to $<10.5 \%$ (for patients who had previously been treated with one OAD in trial NCT00798161). Patients who had received glucose-lowering medication before screening went through a 4-week drug washout period before initiating study treatment. Patients were randomized to receive 24 weeks of treatment with either linagliptin $2.5 \mathrm{mg} / \mathrm{metformin} 500 \mathrm{mg}$ twice daily (bid), or linagliptin $2.5 \mathrm{mg} / \mathrm{metformin} 1000 \mathrm{mg}$ bid or the component monotherapies (metformin $500 \mathrm{mg}$ bid, metformin $1000 \mathrm{mg}$ bid, linagliptin $5 \mathrm{mg}$ once daily); the NCT00798161 trial also had an additional placebo arm. Glycemic rescue therapy with sulfonylureas, thiazolidinediones or insulin was permitted between the start of treatment and week 12 for patients with a glucose level $>240 \mathrm{mg} / \mathrm{dL}$ after an overnight fast or a randomly determined glucose level $>400 \mathrm{mg} / \mathrm{dL}$, and between weeks 12 and 24 for those with a glucose level $>200 \mathrm{mg} / \mathrm{dL}$ after an overnight fast or a randomly determined glucose level $>400 \mathrm{mg} / \mathrm{dL}$. The primary endpoint in both trials was the change in HbA1c from baseline to 24 weeks of treatment. For the study reported here, we pooled and analyzed individual patient data from the following four treatment arms from both trials: linagliptin $2.5 \mathrm{mg} / \mathrm{metformin} 500 \mathrm{mg}$ bid, linagliptin $2.5 \mathrm{mg} / \mathrm{metformin} 1000 \mathrm{mg}$ bid, metformin $500 \mathrm{mg}$ bid, metformin $1000 \mathrm{mg}$ bid.

The trials were approved by the independent ethics committees or institutional review boards of each participating center and were conducted in accordance with the ethical principles of the Declaration of Helsinki (1996) and in compliance with Good Clinical Practice guidelines as defined by the International Conference on Harmonization. All patients gave written, informed consent before participation.

\section{Assessments}

The homogeneity of the study design of these two clinical trials facilitated pooling and analysis of data from the studies. In this pooled analysis, the main outcome of interest was the proportion of patients who met the glycemic control target of $\mathrm{HbA} 1 \mathrm{c} \leq 6.5 \%$ at week 24 . We also analyzed the proportion of patients achieving $\mathrm{HbA} 1 \mathrm{c}<7.0 \%$ at week 24 . For these outcomes, we also evaluated patient subgroups based on baseline HbA1c categories $(<7.5 \%$, $\geq$ 7.5 to $\leq 9.0 \%$ or $>9.0 \%$ ). Additionally, we performed a sensitivity analysis to examine whether achievement of $\mathrm{HbA} 1 \mathrm{c} \leq 6.5 \%$ or $<$ $7.0 \%$ differed for patients without prior glucose-lowering treatment. Other efficacy outcomes included change from baseline to week 24 in HbA1c, fasting plasma glucose and body weight (baseline HbA1c was defined as the last available HbA1c measurement prior to the start of randomized study treatment, excluding values taken before washout). We evaluated treatment tolerability by analyzing the incidence of reported adverse events, including hypoglycemia and gastrointestinal adverse events. We classified adverse events using the Medical Dictionary for Regulatory Activities (MedDRA) version 17.0 (https://www.meddra.org/). Hypoglycemia was defined as a plasma glucose concentration $\leq 70 \mathrm{mg} / \mathrm{dL}$; severe hypoglycemia 
was defined as an episode requiring the assistance of another person to actively administer carbohydrate, glucagon or other resuscitative actions, without necessarily having an accompanying plasma glucose measurement. Gastrointestinal adverse events were defined as any individual event (preferred term) in the MedDRA system organ class of gastrointestinal disorders.

\section{Statistical Analysis}

We evaluated efficacy parameters using data for the full-analysis set, which consisted of all randomized patients who received at least one dose of study drug, had a baseline HbA1c measurement and had at least one HbA1c measurement during treatment. Achievement of $\mathrm{HbA1c}$ targets $(\leq 6.5 \%,<7.0 \%)$ was analyzed using a multivariate logistic regression model that included baseline HbA1c as a linear covariate and study and treatment as fixed factors. For this model, patients receiving glycemic rescue therapy were considered to have failed to achieve the target, while the HbA1c value for patients without glycemic rescue therapy was either derived from the measured value or, if missing, was imputed using the approach of non-completers considered to be failures. Differences between treatment groups in changes from baseline in HbA1c and fasting plasma glucose were evaluated by analysis of covariance using the last observation carried forward approach to impute missing data as well as values obtained after the initiation of glycemic rescue medication, and using the observed cases approach to analyze the change from baseline in body weight. Adverse events were summarized descriptively for the treated set, defined as all patients who were treated with at least one dose of study drug.

\section{RESULTS}

\section{Patient Characteristics}

A total of 1160 patients were included in the pooled analysis. Their clinical and demographic characteristics at baseline were well balanced across treatment groups (Table 1). Mean HbA1c was approximately $8.7 \%$, more than half of patients had had T2D for $\leq 1$ year and almost three-quarters had not been previously treated with a glucose-lowering drug. Fewer than 10\% of patients had diabetic microvascular complications at baseline.

\section{Efficacy}

\section{Percentage of Patients Who Achieved HbA1c $\leq 6.5 \%$ or $<7.0 \%$}

The proportion of patients achieving HbA1c $\leq 6.5 \%$ at 24 weeks was significantly higher with combination therapy than with metformin alone (linagliptin/metformin $500 \mathrm{mg}$ bid vs. metformin $500 \mathrm{mg}$ bid: 40.1 vs. $22.9 \%$, odds ratio [OR] 2.84, 95\% confidence interval [CI] 1.87-4.32, $P<0.0001$; linagliptin/metformin $1000 \mathrm{mg}$ bid vs. metformin $1000 \mathrm{mg}$ bid: 49.5 vs. $35.4 \%$, OR $2.28,95 \%$ CI 1.54-3.40, $P<0.0001$ ) (Table 2).

Among patients with baseline $\mathrm{HbA} 1 \mathrm{c} \geq 7.5 \%$ to $<9.0 \%$, the percentage achieving $\mathrm{HbA} 1 \mathrm{c} \leq$ $6.5 \%$ was significantly higher with the combination treatment than with monotherapy (500 mg metformin: 41.0 vs. $25.1 \%$, OR $2.54,95 \%$ CI $1.52-4.27 ; 1000 \mathrm{mg}$ metformin: 53.0 vs. $36.8 \%$, OR $2.10,95 \%$ CI 1.27-3.48). The percentage of patients achieving $\mathrm{HbA} 1 \mathrm{c} \leq 6.5 \%$ was also greater with combination treatment than monotherapy among those with baseline HbA1c $<7.5 \%$ or $\geq 9.0 \%$, albeit the increases were not always significant (Table 2).

The sensitivity analysis of patients without previous glucose-lowering treatment was consistent with the above findings from the overall population. Early treatment with initial combination of linagliptin and metformin resulted in a higher percentage of patients achieving HbA1c $\leq 6.5 \%$ than metformin alone $(500 \mathrm{mg}$ metformin: 53.6 vs. $30.0 \%$, OR 3.17 , $95 \%$ CI $2.05-4.91 ; 1000 \mathrm{mg}$ metformin: 60.7 vs. $45.5 \%$, OR 2.10, 95\% CI 1.36-3.23) (Table 2).

A similar treatment effect for the initial combination of linagliptin/metformin compared with metformin monotherapy was observed for achievement of HbA1c $<7.0 \%$ (Table 2). 
Table 1 Baseline characteristics of patients in treated set and full-analysis set

\begin{tabular}{|c|c|c|c|c|}
\hline \multirow[t]{2}{*}{ Patient characteristics at baseline } & \multicolumn{4}{|l|}{ Treatment arm } \\
\hline & $\begin{array}{l}\text { MET } 500 \mathrm{mg} \\
\text { bid }\end{array}$ & $\begin{array}{l}\text { LINA/MET } 500 \mathrm{mg} \\
\text { bid }\end{array}$ & $\begin{array}{l}\text { MET } 1000 \mathrm{mg} \\
\text { bid }\end{array}$ & $\begin{array}{l}\text { LINA/MET } \\
1000 \mathrm{mg} \mathrm{bid}\end{array}$ \\
\hline Treated set, $N^{a}$ & 289 & 290 & 291 & 290 \\
\hline Male, $n(\%)$ & $173(59.9)$ & $165(56.9)$ & $169(58.1)$ & $164(56.6)$ \\
\hline Age, years, mean $(\mathrm{SD})$ & $52.5(10.0)$ & $53.5(10.9)$ & $53.3(10.7)$ & $53.5(10.4)$ \\
\hline \multicolumn{5}{|l|}{ Age, years, $n(\%)$} \\
\hline$\leq 50$ & $119(41.2)$ & $119(41.0)$ & $113(38.8)$ & $104(35.9)$ \\
\hline $51-64$ & $130(45.0)$ & $127(43.8)$ & $133(45.7)$ & $142(49.0)$ \\
\hline $65-74$ & $39(13.5)$ & $36(12.4)$ & $42(14.4)$ & $41(14.1)$ \\
\hline$\geq 75$ & $1(0.3)$ & $8(2.8)$ & $3(1.0)$ & $3(1.0)$ \\
\hline \multicolumn{5}{|l|}{ Race, $n(\%)$} \\
\hline White & $93(32.2)$ & $103(35.5)$ & $95(32.6)$ & $94(32.4)$ \\
\hline Black & $0(0.0)$ & $2(0.7)$ & $2(0.7)$ & $1(0.3)$ \\
\hline Asian & $196(67.8)$ & $185(63.8)$ & $194(66.7)$ & $195(67.2)$ \\
\hline Weight, kg, mean (SD) & $74.50(15.96)$ & $75.73(16.60)$ & $75.52(16.32)$ & $73.56(14.40)$ \\
\hline BMI, $\mathrm{kg} / \mathrm{m}^{2}$, mean $(\mathrm{SD})$ & $27.34(4.42)$ & $27.81(4.88)$ & $27.83(4.75)$ & $27.26(4.46)$ \\
\hline \multicolumn{5}{|l|}{ BMI, $\mathrm{kg} / \mathrm{m}^{2}, n(\%)$} \\
\hline$<25$ & $91(31.5)$ & $87(30.0)$ & $92(31.6)$ & $97(33.4)$ \\
\hline $25-30$ & $131(45.3)$ & $120(41.4)$ & $117(40.2)$ & $124(42.8)$ \\
\hline$\geq 30$ & $67(23.2)$ & $83(28.6)$ & $82(28.2)$ & $69(23.8)$ \\
\hline \multicolumn{5}{|l|}{ Comorbidities, $n$ (\%) } \\
\hline Hypertension & $128(44.3)$ & $132(45.5)$ & $131(45.0)$ & $119(41.0)$ \\
\hline Coronary artery disease & $15(5.2)$ & $26(9.0)$ & $20(6.9)$ & $12(4.1)$ \\
\hline Dyslipidemia & $52(18.0)$ & $47(16.2)$ & $39(13.4)$ & $42(14.5)$ \\
\hline \multicolumn{5}{|l|}{ Complications, $n(\%)$} \\
\hline Diabetic nephropathy & $11(3.8)$ & $15(5.2)$ & $8(2.7)$ & $10(3.4)$ \\
\hline Diabetic retinopathy & $8(2.8)$ & $6(2.1)$ & $5(1.7)$ & $8(2.8)$ \\
\hline Full-analysis set, $N^{\mathrm{b}}$ & 285 & 279 & 271 & 281 \\
\hline \multicolumn{5}{|l|}{ Diabetes duration, years, $n(\%)$} \\
\hline$\leq 1$ & $176(61.8)$ & $173(62.0)$ & $153(56.5)$ & $166(59.1)$ \\
\hline$>1-5$ & $67(23.5)$ & $61(21.9)$ & $83(30.6)$ & $70(24.9)$ \\
\hline$>5$ & $42(14.7)$ & $45(16.1)$ & $35(12.9)$ & $45(16.0)$ \\
\hline Antidiabetes drugs at enrollment, & & & & \\
\hline
\end{tabular}


Table 1 continued

\begin{tabular}{|c|c|c|c|c|}
\hline \multirow[t]{2}{*}{ Patient characteristics at baseline } & \multicolumn{4}{|c|}{ Treatment arm } \\
\hline & $\begin{array}{l}\text { MET } 500 \mathrm{mg} \\
\text { bid }\end{array}$ & $\begin{array}{l}\text { LINA/MET } 500 \mathrm{mg} \\
\text { bid }\end{array}$ & $\begin{array}{l}\text { MET } 1000 \mathrm{mg} \\
\text { bid }\end{array}$ & $\begin{array}{l}\text { LINA/MET } \\
1000 \mathrm{mg} \text { bid }\end{array}$ \\
\hline None & $213(74.7)$ & $207(74.2)$ & $200(73.8)$ & $206(73.3)$ \\
\hline Metformin only & $50(17.5)$ & $49(17.6)$ & $53(19.6)$ & $52(18.5)$ \\
\hline Sulfonylurea only & $19(6.7)$ & $22(7.9)$ & $18(6.6)$ & $23(8.2)$ \\
\hline Alpha-glucosidase inhibitor only & $1(0.4)$ & $0(0.0)$ & $0(0.0)$ & $0(0.0)$ \\
\hline Glinide only & $1(0.4)$ & $1(0.4)$ & $0(0.0)$ & $0(0.0)$ \\
\hline Metformin and sulfonylurea & $1(0.4)$ & $0(0.0)$ & $0(0.0)$ & $0(0.0)$ \\
\hline $\mathrm{HbAlc}$ \%, mean (SD) & $8.68(0.98)$ & $8.68(0.94)$ & $8.57(0.93)$ & $8.71(1.02)$ \\
\hline \multicolumn{5}{|l|}{$\mathrm{HbAlc}, \%, n$} \\
\hline$<7.5$ & 18 & 20 & 26 & 26 \\
\hline $7.5-9.0$ & 171 & 161 & 163 & 151 \\
\hline$\geq 9.0$ & 96 & 98 & 82 & 104 \\
\hline $\begin{array}{l}\text { Fasting plasma glucose, } \mathrm{mg} / \mathrm{dL} \text {, } \\
\text { mean (SD) }\end{array}$ & $182.5(46.3)$ & $182.7(52.9)$ & $181.2(47.3)$ & $181.8(46.7)$ \\
\hline
\end{tabular}

bid Twice daily, BMI body-mass index, HbAIc glycated hemoglobin Alc, LINA linagliptin, MET metformin, SD standard deviation

${ }^{a} N=1160$. The treated set included all patients who were treated with at least one dose of study drug

b $N=1116$. The full-analysis set included all patients who were randomized and treated with at least one dose of study drug, had a baseline $\mathrm{HbAlc}$ measurement and at least one HbAlc measurement during treatment

\section{Change from Baseline in $\mathrm{HbA1}$, Fasting Plasma Glucose and Body Weight}

Significantly greater reductions in HbA1c from baseline were observed with combination therapy than with metformin alone: adjusted mean differences were $-0.53 \%$ with linagliptin/metformin $500 \mathrm{mg}$ bid compared with metformin $500 \mathrm{mg}$ bid, and $-0.36 \%$ with linagliptin/ metformin $1000 \mathrm{mg}$ bid compared with metformin $1000 \mathrm{mg}$ bid (Table 3). The additive effect of linagliptin also resulted in significant reductions in fasting plasma glucose relative to metformin monotherapy (Table 3). Change from baseline in body weight at 24 weeks was minimal in all treatment groups (ranging from $-0.87 \mathrm{~kg}$ to $-0.20 \mathrm{~kg}$ ), with no significant differences between the combination and monotherapy groups.

\section{Safety and Tolerability}

The incidence of patients with adverse events was similar among treatment groups (Table 4), and the majority of adverse events were of mild or moderate intensity. Hypoglycemia was rarely reported, occurring in $<3 \%$ of patients overall, $2.4 \%$ of those receiving linagliptin/metformin $500 \mathrm{mg}$ bid, $1.0 \%$ of those receiving metformin $500 \mathrm{mg}$ bid alone, $1.0 \%$ of those receiving linagliptin/metformin $1000 \mathrm{mg}$ bid and $2.4 \%$ of those receiving metformin $1000 \mathrm{mg}$ bid alone. The only individual to report severe hypoglycemia was a patient receiving metformin $1000 \mathrm{mg}$ bid (Table 4). As expected, gastrointestinal adverse events were more common in groups receiving high-dose metformin (20.6 and $20.3 \%$ for metformin $1000 \mathrm{mg}$ bid alone 


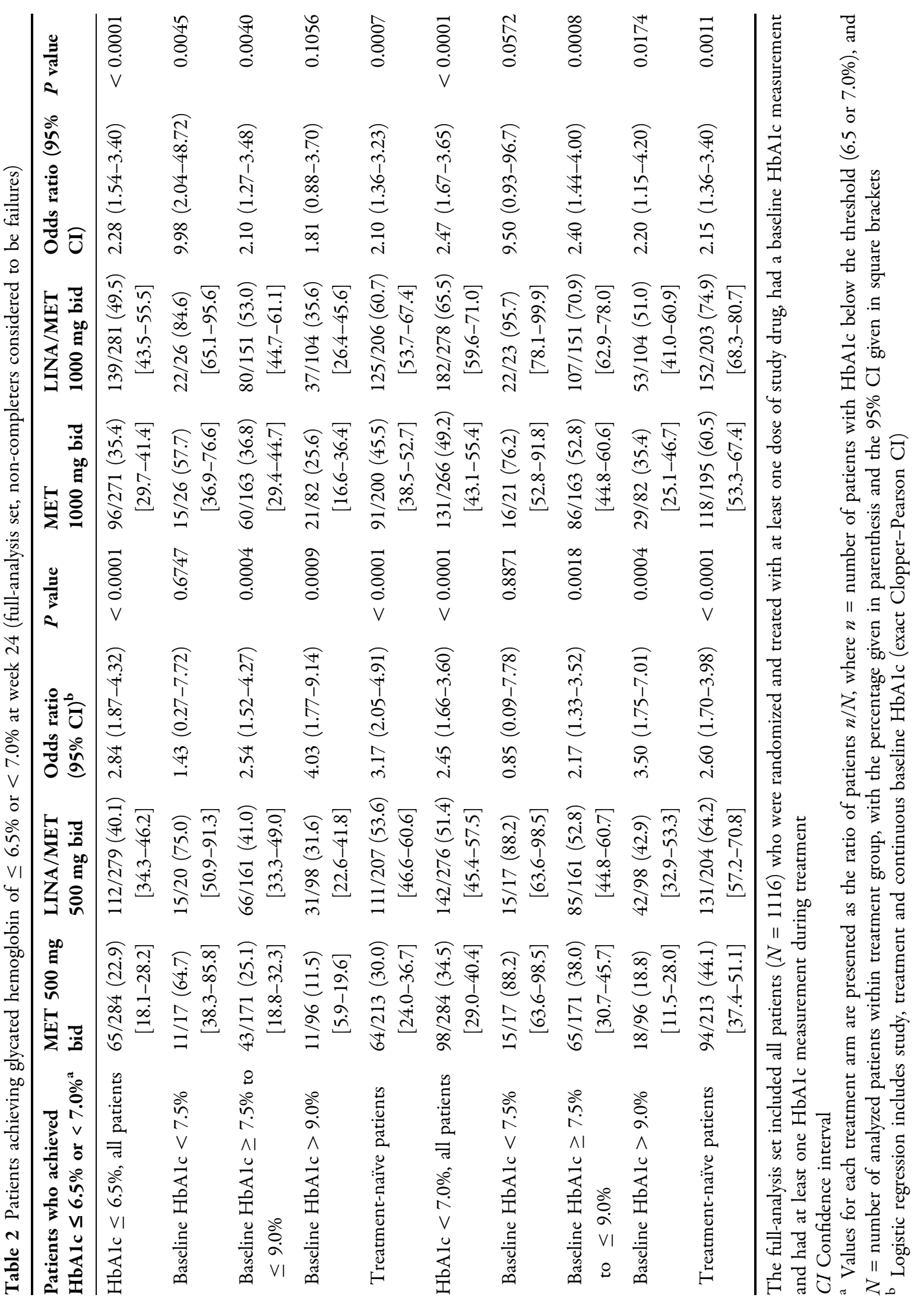




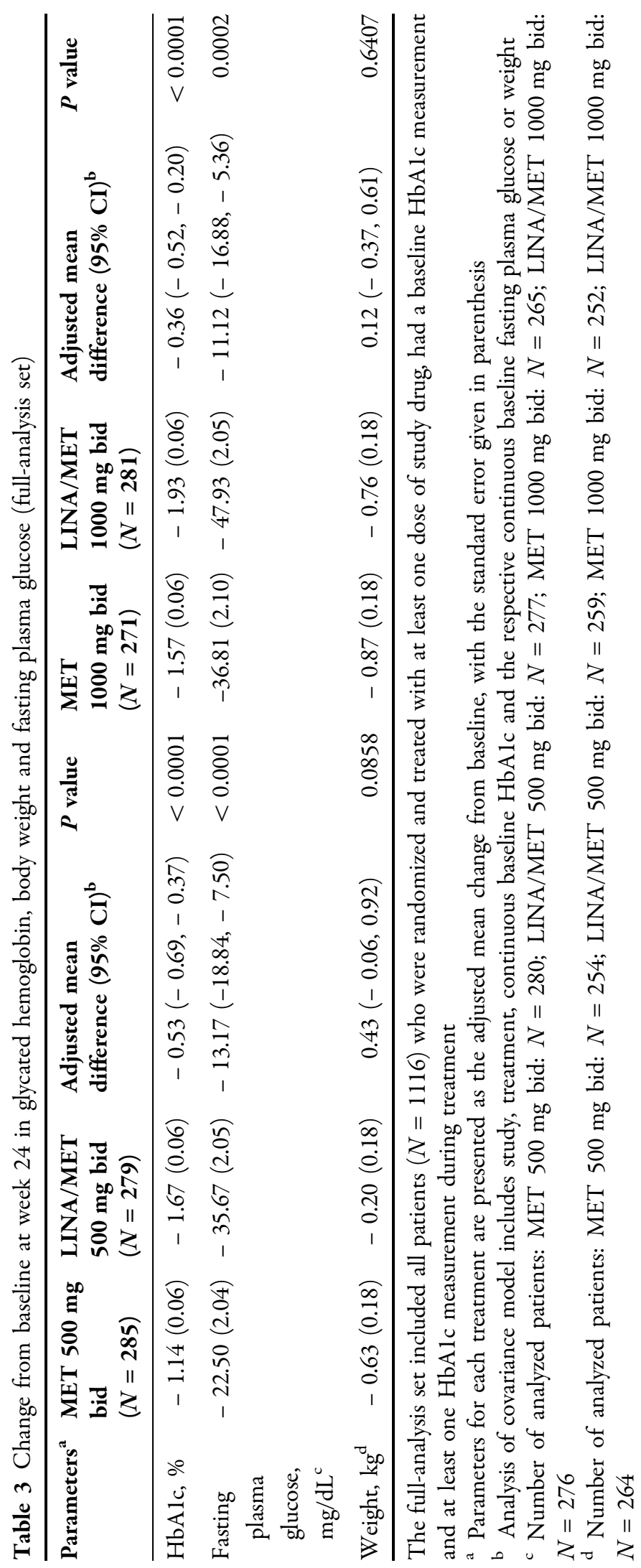


Table 4 Summary of adverse events (treated set)

\begin{tabular}{|c|c|c|c|c|}
\hline \multirow{2}{*}{ Adverse events $^{a}$} & \multicolumn{4}{|l|}{ Treatment arm } \\
\hline & $\begin{array}{l}\text { MET } 500 \mathrm{mg} \\
\text { bid }(N=289)\end{array}$ & $\begin{array}{l}\text { LINA/MET } 500 \mathrm{mg} \\
\text { bid }(N=290)\end{array}$ & $\begin{array}{l}\text { MET } 1000 \mathrm{mg} \\
\text { bid }(N=291)\end{array}$ & $\begin{array}{l}\text { LINA/MET } \\
1000 \mathrm{mg} \text { bid } \\
(N=290)\end{array}$ \\
\hline All adverse events & $149(51.6)$ & $146(50.3)$ & $159(54.6)$ & $155(53.4)$ \\
\hline Serious adverse events & $4(1.4)$ & $3(1.0)$ & $8(2.7)$ & $6(2.1)$ \\
\hline $\begin{array}{l}\text { Adverse events leading to } \\
\text { discontinuation of study drug }\end{array}$ & $6(2.1)$ & $7(2.4)$ & $15(5.2)$ & $9(3.1)$ \\
\hline Any hypoglycemia & $3(1.0)$ & $7(2.4)$ & $7(2.4)$ & $3(1.0)$ \\
\hline Severe hypoglycemia & $0(0.0)$ & $0(0.0)$ & $1(0.3)$ & $0(0.0)$ \\
\hline Gastrointestinal adverse events & $37(12.8)$ & $46(15.9)$ & $60(20.6)$ & $59(20.3)$ \\
\hline
\end{tabular}

Values in table are presented as a number (of patients) with the percentage in parenthesis

The treated set included all patients $(N=1160)$ who were treated with at least one dose of study drug

a The Medical Dictionary for Regulatory Activities version 17.0 (https://www.meddra.org/) was used for reporting adverse events

and linagliptin/metformin $1000 \mathrm{mg}$ bid, respectively) (Table 4). No cases of pancreatitis were reported.

\section{DISCUSSION}

In this pooled analysis of two randomized clinical trials, initial combination therapy with the DPP-4 inhibitor linagliptin and metformin significantly increased the percentage of patients with early T2D achieving HbA1c $\leq 6.5 \%$ after 24 weeks of treatment, compared with metformin monotherapy, without increasing the risk for hypoglycemia. This is a novel finding, as achievement of tight glycemic control $(\mathrm{HbA} 1 \mathrm{c} \leq 6.5 \%)$ was not uniformly reported for the two underlying clinical trials. These patients had a relatively short duration of diabetes and few diabetic complications and were mostly treatment naive. The addition of linagliptin to low-dose metformin (500 mg bid) almost doubled the number of patients achieving $\mathrm{HbA} 1 \mathrm{c} \leq 6.5 \%$ (from $22.9 \%$ with metformin monotherapy to $40.1 \%$ with linagliptin/ metformin). The addition of linagliptin to higher-dose metformin (1000 mg bid) resulted in almost half the patients achieving this glycemic goal (35.4\% with metformin $1000 \mathrm{mg}$; $49.5 \%$ with linagliptin/metformin $1000 \mathrm{mg}$ ). Importantly, the incidence of hypoglycemia was very low (1.0-2.4\%) and comparable among treatment groups. These findings suggest that combining metformin with linagliptin in early T2D can safely improve the chances of achieving tight glycemic control.

In landmark clinical trials, intensive glucoselowering treatment designed to achieve tight glycemic control (typically HbA1c $\leq 6.5$ ) led to significantly lower rates of long-term microvascular complications $[11,13,14]$ and, possibly, lower risk of myocardial infarction [12]. However, this strategy also substantially increased the risk of hypoglycemia when high doses of sulfonylureas were used for intensive glucoselowering therapy, as observed in the ADVANCE [14] and ACCORD [13] studies. Furthermore, intensive glucose lowering was associated with an increased risk for mortality in ACCORD. Unlike ACCORD, which was conducted in patients with advanced T2D [13], the previous UK Prospective Diabetes Study (UKPDS) enrolled newly diagnosed T2D patients [11]. The UKPDS found that intensive glucose-lowering 
treatment with insulin or sulfonylureas targeting fasting plasma glucose $<108 \mathrm{mg} / \mathrm{dL}$ improved microvascular outcomes compared with conventional treatment (diet alone, at that time) [11]. Furthermore, intensive treatment appeared to have a legacy effect in which microvascular benefits were maintained and macrovascular risk reduction emerged 10 years after discontinuation of randomized interventions, with subsequent convergence of glycemic control in both groups [12]. Nevertheless, the mortality results from the more recent ACCORD trial may have influenced clinical guidelines moving away from recommending tight glycemic control for all T2D patients and towards a more individualized approach.

Current guidelines from the ADA and AACE, for example, recommend individualized glycemic control targets for different patient groups $[17,18]$. HbA1c $\leq 6.5 \%$ is suggested as a treatment target for T2D patients who have had diabetes for only a short time, who have few comorbidities and/or who have long life expectancy-provided such tight glycemic control can be achieved without hypoglycemia or other iatrogenic adverse effects [17, 18]. Clinical guidelines in China [3], Japan [4] and India [5] are largely in accordance with these recommendations. Compared with classical glucose-lowering drugs used as add-on to metformin (insulin, sulfonylureas), more modern medications, such as DPP-4 inhibitors and SGLT2 inhibitors, may provide better options for tight glycemic control regimens, since they can significantly lower glucose without normally increasing the risk of hypoglycemia. Despite this, HbA1c $<7.0 \%$ remains the goal for most T2D patients, including those who could benefit from a stricter target of $\leq 6.5 \%$.

As our study shows, combining linagliptin with metformin can safely lower blood glucose levels without causing hypoglycemia or other adverse effects, such as weight gain. These findings are consistent with those from previous studies, either in patients with inadequately controlled T2D on metformin [25-27] or in patients with newly diagnosed T2D and marked hyperglycemia [28]. Furthermore, the recent CAROLINA trial found that linagliptin had long-term cardiovascular safety compared with glimepiride, a sulfonylurea, in patients with early T2D and insufficient glycemic controlmost of whom were receiving metformin-based regimens at baseline-but caused substantially less hypoglycemia than this widely prescribed sulfonylurea [29]. Previously, the CARMELINA outcomes trial had demonstrated the long-term cardiovascular and kidney safety profile of linagliptin compared with placebo in T2D patients with high cardiovascular and renal risk [30]. Again, linagliptin did not increase the risk of hypoglycemia compared with placebo even in these high-risk patients prone to hypoglycemia [30].

CAROLINA and CARMELINA are among the wave of cardiovascular outcomes trials of glucose-lowering drugs over the past decade that have influenced clinical guidelines. Based on the results of these studies, the latest joint consensus report from the ADA and EASD recommends that patients with indicators of high cardiovascular risk, established cardiovascular disease, heart failure or chronic kidney disease receive second-line treatment with a glucoselowering drug that has proven cardiovascular benefit, such as an SGLT2 inhibitor or a GLP-1 receptor agonist [19]. For others, the consensus report recommends DPP-4 inhibitors, including linagliptin, as one of the options to add to metformin when there is a compelling need to avoid hypoglycemia [19].

Clinical guidelines differ in their recommendations for when to consider initial combination therapy. The ADA suggests that patients who have $\mathrm{HbA1c} \geq 1.5 \%$ above their glycemic target at the time of diagnosis should start with combination therapy [31]; this would equate in most cases to a HbA1c of $\geq 8.5 \%$ or $\geq 8.0 \%$ based on the ADA targets of HbA1c $<7.0 \%$ for most patients and HbA1c of $<6.5 \%$ for certain other patients [17]. In contrast, the AACE guidelines suggest $\mathrm{HbA} 1 \mathrm{c} \geq 7.5 \%$ as the level at which combination therapy should be initiated [18]. Results from our analysis support the AACE recommendation as, compared with monotherapy, significantly more patients receiving initial combination treatment achieved HbA1c $\leq 6.5 \%$ if they had a baseline HbA1c between 7.5 and $9.0 \%$. However, in patients with baseline HbA1c $>9.0 \%$, although 
combination therapy numerically improved the proportion achieving $\mathrm{HbA} 1 \mathrm{c} \leq 6.5 \%$, the majority still did not reach this target-not unexpectedly, given the high baseline level; adding another OAD or insulin to the combination therapy may be considered for such patients, as suggested by the AACE guidelines [18]. The ADA treatment guidelines suggest considering the early introduction of insulin for patients with $\mathrm{HbA} 1 \mathrm{c}>10 \%$ [31]. Finally, in patients with baseline $\mathrm{HbA} 1 \mathrm{c}<7.5 \%$ in our study, the linagliptin/metformin combination was more efficacious than metformin monotherapy for achieving $\mathrm{HbA} 1 \mathrm{c} \leq 6.5 \%$ or $<7.0 \%$ only at the higher dose of metformin $(1000 \mathrm{mg})$, but the majority of patients with baseline $\mathrm{HbA} 1 \mathrm{c}<7.5 \%$ in all treatment groups achieved these targets. Future guidelines on initial combination therapy are also likely to be impacted by the recent 5-year VERIFY study, in which initial combination treatment with the DPP-4 inhibitor vildagliptin and metformin in newly diagnosed T2D patients with HbA1c $6.5-7.5 \%$ provided greater and more durable glycemic control than metformin monotherapy [32].

There are several limitations to our pooled analysis. Firstly, its retrospective nature restricted the data available for analysis; consequently, although we included patients with a relatively short duration of diabetes, we were unable to clearly define whether any given patient was suitable for an individualized glycemic control target of $\mathrm{HbA} 1 \mathrm{c} \leq 6.5 \%$. Secondly, due to the short duration of the underlying trials, we could not determine whether achieving a lower HbA1c target by early combination therapy results in long-term stable glycemic control; longer randomized studies would be needed to confirm the durable efficacy of the linagliptin/metformin combination. Thirdly, early combination therapy was compared with continuation of metformin monotherapy, which does not reflect the common clinical practice of sequential add-on therapy, although it is in keeping with the fact that in clinical practice, patients may experience protracted periods of poor glycemic control [33]. This delayed intervention (clinical inertia) is associated with an increased risk of complications [34].

\section{CONCLUSIONS}

Our pooled analysis suggests that the early combination therapy of linagliptin and metformin can help improve the treatment of T2D compared with metformin monotherapy, in terms of achieving tight glycemic control $(\mathrm{HbA} 1 \mathrm{c} \leq 6.5 \%)$ without increasing the risk of hypoglycemia or other adverse effects.

\section{ACKNOWLEDGEMENTS}

The authors thank Dr. Sandra van der Walt and Uwe Hehnke from Boehringer Ingelheim for their assistance with the study design and data analysis.

Funding. This study was supported by the Boehringer Ingelheim and Eli Lilly and Company Diabetes Alliance, which also funded the Rapid Service Fee for publication of this paper.

Medical Writing Assistance. Medical writing assistance, supported financially by Boehringer Ingelheim, was provided by Giles Brooke, PhD, CMPP, of Elevate Scientific Solutions and Liang Zhou of Shanghai INNSCI Information \& Technology Co., Ltd. during the preparation of this manuscript.

Authorship. All named authors meet the International Committee of Medical Journal Editors (ICMJE) criteria for authorship for this article, take responsibility for the integrity of the work as a whole, and have given their approval for this version to be published.

Prior Presentation. Data from this study have previously been presented at the 54th Annual Meeting of the European Association for the Study of Diabetes, Berlin, Germany, 1-5 October 2018 (Diabetologia 2018;61[Suppl 1]:S378 [poster 771]). 
Disclosures. Qian Lv has nothing to disclose. Jie Shen, Binqi Ye and Cornelia Schepers are employees of Boehringer Ingelheim. Lin Miao is an employee of Eli Lilly and Company. Arian Plat is an employee of Boehringer Ingelheim and Eli Lilly and Company. Yongquan Shi is a speaker/advisory panel member for Eli Lilly and Company, Boehringer Ingelheim, AstraZeneca, Bayer, Novartis, Novo Nordisk, Sanofi and MSD.

Compliance with Ethics Guidelines. The trials were approved by the independent ethics committees or institutional review boards of each participating center and were conducted in accordance with the ethical principles of the Declaration of Helsinki (1996) and in compliance with Good Clinical Practice guidelines as defined by the International Conference on Harmonization. All patients gave written, informed consent before participation.

Data Availability. The sponsor of the clinical trials (Boehringer Ingelheim) is committed to responsible sharing of clinical study reports, related clinical documents, and patient-level clinical study data. Researchers are invited to submit inquiries via the following website (https://trials.boehringer-ingelheim.com).

Open Access. This article is licensed under a Creative Commons Attribution-NonCommercial 4.0 International License, which permits any non-commercial use, sharing, adaptation, distribution and reproduction in any medium or format, as long as you give appropriate credit to the original author(s) and the source, provide a link to the Creative Commons licence, and indicate if changes were made. The images or other third party material in this article are included in the article's Creative Commons licence, unless indicated otherwise in a credit line to the material. If material is not included in the article's Creative Commons licence and your intended use is not permitted by statutory regulation or exceeds the permitted use, you will need to obtain permission directly from the copyright holder. To view a copy of this licence, visit http://creativecommons.org/licenses/by$\mathrm{nc} / 4.0 /$.

\section{REFERENCES}

1. Kahn SE, Cooper ME, Del Prato S. Pathophysiology and treatment of type 2 diabetes: perspectives on the past, present, and future. Lancet. 2014;383(9922):1068-83.

2. Davies MJ, D’Alessio DA, Fradkin J, et al. Management of hyperglycemia in type 2 diabetes, 2018. A consensus report by the American Diabetes Association (ADA) and the European Association for the Study of Diabetes (EASD). Diabetes Care. 2018;41(12):2669-701.

3. Jia W, Weng J, Zhu D, et al. Standards of medical care for type 2 diabetes in China 2019. Diabetes Metab Res Rev. 2019;35:e3158.

4. Haneda $M$, Noda $M$, Origasa $H$, et al. Japanese clinical practice guideline for diabetes 2016. J Diabetes Investig. 2018;9(1):1-45.

5. Bajaj S. RSSDI clinical practice recommendations for the management of type 2 diabetes mellitus 2017. Int J Diabetes Dev Ctries. 2018;38[Suppl 1]: $1-115$.

6. Higgins V, Piercy J, Roughley A, et al. Trends in medication use in patients with type 2 diabetes mellitus: a long-term view of real-world treatment between 2000 and 2015. Diabetes Metab Syndr Obes. 2016;9:371-80.

7. Ali MK, Bullard KM, Saaddine JB, Cowie CC, Imperatore G, Gregg EW. Achievement of goals in U.S. diabetes care, 1999-2010. N Engl J Med. 2013;368(17):1613-24.

8. de Pablos-Velasco P, Parhofer KG, Bradley C, et al. Current level of glycaemic control and its associated factors in patients with type 2 diabetes across Europe: data from the PANORAMA study. Clin Endocrinol (Oxf). 2014;80(1):47-56.

9. Shivashankar R, Kirk K, Kim WC, et al. Quality of diabetes care in low- and middle-income Asian and Middle Eastern countries (1993-2012): 20-year systematic review. Diabetes Res Clin Pract. 2015;107(2):203-23.

10. Carls G, Huynh J, Tuttle E, Yee J, Edelman SV. Achievement of glycated hemoglobin goals in the US remains unchanged through 2014. Diabetes Ther. 2017;8(4):863-73.

11. UK Prospective Diabetes Study (UKPDS) Group. Intensive blood-glucose control with sulphonylureas or insulin compared with conventional treatment and risk of complications in patients 
with type 2 diabetes (UKPDS 33). Lancet. 1998;352(9131):837-53.

12. Holman RR, Paul SK, Bethel MA, Matthews DR, Neil HA. 10-year follow-up of intensive glucose control in type 2 diabetes. N Engl J Med. 2008;359(15): 1577-89.

13. Action to Control Cardiovascular Risk in Diabetes Study Group, Gerstein HC, Miller ME, et al. Effects of intensive glucose lowering in type 2 diabetes. N Engl J Med. 2008;358(24):2545-59.

14. ADVANCE Collaborative Group, Patel A, MacMahon $\mathrm{S}$, et al. Intensive blood glucose control and vascular outcomes in patients with type 2 diabetes. N Engl J Med. 2008;358(24):2560-72.

15. Bianchi C, Daniele G, Dardano A, Miccoli R, Del Prato S. Early combination therapy with oral glucose-lowering agents in type 2 diabetes. Drugs. 2017;77(3):247-64.

16. Zonszein J, Groop PH. Strategies for diabetes management: using newer oral combination therapies early in the disease. Diabetes Ther. 2016;7(4): 621-39.

17. American Diabetes Association. 6. Glycemic targets: standards of medical care in diabetes-2019. Diabetes Care. 2019;42[Suppl 1]:S61-S70.

18. Garber AJ, Abrahamson MJ, Barzilay JI, et al. Consensus statement by the American Association of Clinical Endocrinologists and American College of Endocrinology on the comprehensive type 2 diabetes management algorithm-2019 executive summary. Endocr Pract. 2019;25(1):69-100.

19. Buse JB, Wexler DJ, Tsapas A, et al. 2019 Update to: management of hyperglycemia in type 2 diabetes, 2018. A consensus report by the American Diabetes Association (ADA) and the European Association for the Study of Diabetes (EASD). Diabetes Care. 2020;43(2):487-93.

20. Phung OJ, Sobieraj DM, Engel SS, Rajpathak SN. Early combination therapy for the treatment of type 2 diabetes mellitus: systematic review and meta-analysis. Diabetes Obes Metab. 2014;16(5): 410-7.

21. Hadjadj S, Rosenstock J, Meinicke T, Woerle HJ, Broedl UC. Initial combination of empagliflozin and metformin in patients with type 2 diabetes. Diabetes Care. 2016;39(10):1718-28.

22. Rosenstock J, Chuck L, Gonzalez-Ortiz M, et al. Initial combination therapy with canagliflozin plus metformin versus each component as monotherapy for drug-naive type 2 diabetes. Diabetes Care. 2016;39(3):353-62.
23. Mu Y, Pan C, Fan B, et al. Efficacy and safety of linagliptin/metformin single-pill combination as initial therapy in drug-naive Asian patients with type 2 diabetes. Diabetes Res Clin Pract. 2017;124: $48-56$.

24. Haak T, Meinicke T, Jones R, Weber S, von Eynatten $\mathrm{M}$, Woerle HJ. Initial combination of linagliptin and metformin improves glycaemic control in type 2 diabetes: a randomized, double-blind, placebocontrolled study. Diabetes Obes Metab. 2012;14(6): 565-74.

25. Forst $\mathrm{T}$, Uhlig-Laske B, Ring A, et al. Linagliptin (BI 1356), a potent and selective DPP-4 inhibitor, is safe and efficacious in combination with metformin in patients with inadequately controlled type 2 diabetes. Diabet Med. 2010;27(12):1409-19.

26. Ross SA, Rafeiro E, Meinicke T, Toorawa R, WeberBorn S, Woerle HJ. Efficacy and safety of linagliptin $2.5 \mathrm{mg}$ twice daily versus $5 \mathrm{mg}$ once daily in patients with type 2 diabetes inadequately controlled on metformin: a randomised, double-blind, placebo-controlled trial. Curr Med Res Opin. 2012;28(9):1465-74.

27. Taskinen MR, Rosenstock J, Tamminen I et al. Safety and efficacy of linagliptin as add-on therapy to metformin in patients with type 2 diabetes: a randomized, double-blind, placebo-controlled study. Diabetes Obes Metab. 2011;13(1):65-74.

28. Ross SA, Caballero AE, Del Prato S, et al. Initial combination of linagliptin and metformin compared with linagliptin monotherapy in patients with newly diagnosed type 2 diabetes and marked hyperglycaemia: a randomized, double-blind, active-controlled, parallel group, multinational clinical trial. Diabetes Obes Metab. 2015;17(2): 136-44.

29. Rosenstock J, Kahn SE, Johansen OE, et al. Effect of linagliptin vs glimepiride on major adverse cardiovascular outcomes in patients with type 2 diabetes: the CAROLINA randomized clinical trial. JAMA. 2019;322(12):1155-66.

30. Rosenstock J, Perkovic V, Johansen OE, et al. Effect of linagliptin vs placebo on major cardiovascular events in adults with type 2 diabetes and high cardiovascular and renal risk: the CARMELINA randomized clinical trial. JAMA. 2019;321(1):69-79.

31. American Diabetes Association. 9. Pharmacologic approaches to glycemic treatment: standards of medical care in diabetes-2019. Diabetes Care. 2019;42[Suppl 1]:S90-S102.

32. Matthews DR, Paldanius PM, Proot P, et al. Glycaemic durability of an early combination therapy with vildagliptin and metformin versus sequential 
metformin monotherapy in newly diagnosed type 2 diabetes (VERIFY): a 5-year, multicentre, randomised, double-blind trial. Lancet. 2019;394(10208):1519-29.

33. Khunti K, Wolden ML, Thorsted BL, Andersen M, Davies MJ. Clinical inertia in people with type 2 diabetes: a retrospective cohort study of more than 80,000 people. Diabetes Care. 2013;36(11):3411-7.

34. Paul SK, Klein K, Thorsted BL, Wolden ML, Khunti $\mathrm{K}$. Delay in treatment intensification increases the risks of cardiovascular events in patients with type 2 diabetes. Cardiovasc Diabetol. 2015;14:100. 